\title{
A LINGUAGEM DO PODER: O FENÔMENO HISTÓRICO-SOCIAL DA COERÇÃO
}

\section{The Language of Power: The Historical - Social Phenomenon of Coercion}

Irineu Colombo ${ }^{1}$

\section{Resumo}

O artigo aborda a possibilidade teórica e metodológica de descortinar, pela análise da linguagem, a forma de poder e as especificidades da coerção numa instituição total. Os mecanismos de poder construídos historicamente, desde a sanção social até a solitária de uma prisão, compõem o poder político do estado e também operam para além dele. A avaliação da linguagem empregada na coerção pode revelar uma ética prisional e a cultura coercitiva dos agentes de estado.

Palavras-chave: Estado, Linguagem, Coerção, Instituição total, Poder.

\section{Abstract}

The article discusses the theoretical and methodological possibility of dissecting, through the analysis of the language, the form of power and the specifications of coercion within a total institution. The mechanics of power built historically, from the social sanction to the solitary, compose the political power of state that also works beyond them. The avaliation of the language used in coercion can reveal professional ethics and a coercisive culture of the agents of the state.

Keywords: State, Language, Coercion, Total institutions, Power.

1 Professor do CEFET-PR, graduado em História, Mestre em Educação (UFPR), doutorando em História Social (UnB). Autor do livro Educação Básica: perguntas e respostas sobre a legislação e a atividade docente (Reproset: Curitiba, 2004), membro da Comissão de Educação e Cultura da Câmara Federal. colombo@medianeira.com.br ou colombo1310@hotmail.com

Revista de Filosofia, Curitiba, v. 18 n. 21, p. 27-44, jul./dez. 2005. 


\section{A coerção como mecanismo de poder}

A linguagem da coerção, da sanção social, do controle dos comportamentos, que configura a psique e o corpo, é a mesma que deu origem aos mecanismos de poder e forjaram as normas de direito apropriadas no surgimento do estado. Se vasculharmos estes vestígios, descobriremos o poder do estado, amparado na legalidade. Mas, se avançarmos mais ainda na análise, perceberemos como atua o poder fora do estado e das instituições, não seria exatamente ilegal, mas pertencente ao mundo da cultura e das práticas decorrentes dela, daquilo que podemos chamar de vestígios de uma linguagem do proto-estado. Temos a possibilidade teórica e metodológica de descortinar, pela análise da linguagem, a forma de poder e as especificidades culturais da coerção numa instituição.

Este artigo trata da coenção como um fenômeno que penetra todos os poros da sociedade. Alguns mecanismos coercitivos são sutis, outros desenvolvidos e refinados ao longo do tempo. A coerção atua para impor ou amoldar o comportamento, sendo a prisão um dos mecanismos coercitivos preponderantes e de uso comum para a punição de crimes. A prisão produz efeitos comportamentais externos, para a sociedade, e internos, para a comunidade carcerária. É um mecanismo somatório das tecnologias do poder e da disciplina que produz o controle e a vigilância sobre a criminalidade, gerando uma ética de conduta prisional, inclusive com uma linguagem própria, que revela o caráter da cultura de coerção. Mostramos que "a própria linguagem é uma forma de controle social" e que pode denotar especificidades da coerção (MELOSSI, 1992, p. 195).

Quando alguém diz 'bom dia', a outra pessoa não está obrigada a responder ou dar atenção, contudo estará à mercê dos constrangimentos costumeiros, sendo taxada de chata ou antipática, além das sanções como exclusão do convívio amistoso. Este tipo sutil de coerção poderá induzir a pessoa em outra ocasião a responder ao cumprimento. A coerção sutil atua na forma de sanção social. Este é um exemplo de que os mecanismos coercitivos podem ser tênues, como na linguagem, gestos, atitudes à mesa, ou, contundentes, agindo sobre o corpo e a mente, como a solitária de uma prisão. Todos eles foram desenvolvidos historicamente e amplamente usados no meio social.

Revista de Filosofia, Curitiba, v. 18 n. 21, p. 27-44, jul./dez. 2005. 
Com o surgimento do estado, num sentido lato, a coerção ganhou norma positiva que compõe o universo do direito. Contudo, o direito não se resume à norma, pois ele está para além da legalidade, decorre das práticas de si, prática do poder e do governo ao longo de séculos (EWALD, 2000, p. 157).

Ocorrendo um delito, um crime ou uma infração, pode-se descrevê-los, isso não muda. Pode-se avaliá-lo, isso muda com o tempo. Ao relacioná-lo com a legislação, pode-se percebê-lo antes de surgirem as leis e antes de surgir qualquer tipo de controle social. Podemos percebêlo ao longo da história e nas diferentes formas de controle e chegaremos aos códigos atuais e às instituições de reclusão. Portanto, aqui, pretendemos demonstrar como o delito tem abordagem histórica diversa na linguagem e na forma de controle, até chegarmos ao usual formato de apartação social. Devemos considerar a "ordem jurídica como mera abstração das relações sociais de produção" e que a ordem jurídica tem diversos formatos ao longo do tempo (ADORNO, Prefácio in FAUSTO, 2001, p. 11). Como afirma François Ewald (2000), "não foram apenas os conteúdos normativos que mudaram, mas a forma, a estrutura, a lógica, a epistemologia jurídica" (EWALD, 2000, p.158).

A coerção é a atuação de mecanismos de punição, vigilância, controle e correção, sobre um comportamento, crime ou infração. Podem agir como estímulo positivo, por meio de elogios, prêmios, recompensas ou oferecendo privilégios. Podem ser por estímulos negativos, por meio da repreensão, constrangimento, suplício ou retenção. Estes mecanismos foram desenvolvidos ao longo do tempo, tornaram-se mais eficientes e econômicos, menos intensos, com aparente humanização e mudando o objetivo de tal forma que atinja mais a alma que o corpo (FOUCAULT, 1999, p. 18). A coerção é definida pelos dicionários como um ato de constrangimento, repreensão, restrição de direitos, limitação ou agir forçando uma atitude. Juridicamente é definida como uma força que emana da soberania do Estado e é capaz de impor o respeito à norma legal.

A ação coercitiva atua como força contra os desviantes da sociedade disciplinar, desde o comportamento esperado à mesa até contra os delitos. $\mathrm{O}$ disciplinamento ocorre, principalmente, como controle numa relação punição e recompensa, desde os níveis mais simples (por exemplo, chamar a atenção ou elogiar) até a punição mais dura, regrada em lei (por exemplo, o isolamento carcerário).

Revista de Filosofia, Curitiba, v. 18 n. 21, p. 27-44, jul./dez. 2005. 
Um crime ou delito diz respeito a um ato que altera a relação social, trazendo um dano material, humano, físico ou moral. "O crime está para a criminalidade assim como a doença isolada está para a endemia. [...] Haverá sempre doentes e doenças, embora isso não signifique a sobrevivência, para sempre, das endemias" (PELLEGRINO, 1992, p. 102). Segundo Boris Fausto (2001), criminalidade "se refere ao fenômeno social na sua dimensão mais ampla, permitindo o estabelecimento de padrões através da constatação de regularidades e cortes", enquanto que crime "diz respeito ao fenômeno na sua singularidade, cuja riqueza em certos casos não se encerra em si mesmo, como caso individual, mas abre caminho para muitas percepções" (FAUSTO, 2001, p. 19).

A primeira constatação é a de que a criminalidade é um fenômeno social, um sintoma, por estar ocorrendo uma perturbação tal que leva a ocorrer o crime. Este permite uma análise do ponto de vista do indivíduo, seu aspecto psicológico e as condições sociais e materiais que o envolvem. A criminalidade permite análise dos fatores desencadeadores, da regularidade, da relação causa-efeito e do resultado efetivo das punições.

“A criminalidade é efeito, é forma perversa de protesto, gerada por uma patologia social que a antecede" para tanto, percebemos que os mecanismos adotados historicamente são usados para a vigilância e controle (PELLEGRINO, 1992, p. 104). O crime, "possibilidade inarredável do ser da existência humana", além de estar sob os mecanismos de controle e vigilância, sofre os efeitos da judicialização e punição, mecanismos de coerção variável de acordo com o tipo de crime e a época em que foi praticado (PELLEGRINO, 1992, p. 102). Os mecanismos de coerção sobre o crime modificam o nível de criminalidade. 0 crime não é histórico, mas os mecanismos de coerção e a criminalidade o são.

O delito nas sociedades germânicas era regulado não pela recomposição da falta, mas pela vingança, que poderia ser mediado por um árbitro que poderia estabelecer esta vingança pelo pagamento em dinheiro. O conflito não se resolve com um elemento neutro que investigará quem tem razão, mas é governado pela luta e transação. Esta poderia ser negociada por meio de um árbitro. Com a invasão dos romanos, um novo sistema começa a surgir. A busca da verdade do acometimento do delito, por meio de prova binária (força física, convencimento verbal) em que a terceira força atuava apenas para conferir a regularidade dos procedimentos.

Revista de Filosofia, Curitiba, v. 18 n. 21, p. 27-44, jul./dez. 2005. 
Esse sistema de práticas judiciánias desaparece no fim do século XII e no curso do século XIII. Toda a segunda metade da Idade Média vai assistir à transformação destas velhas práticas e à invenção de novas formas de justiça, de novas formas de práticas e procedimentos judiciários. Formas que são absolutamente capitais para a história da Europa e para a história do mundo inteiro, na medida em que a Europa impôs violentamente o seu jugo à superfície da terra (FOUCAULT, 2001, p. 62).

Estas novas práticas jurídicas incluirão o inquérito, as buscas de provas mediadas por um poder exterior, que se impõe como poder judiciário e poder político. Após o procedimento judicial, as penas impostas ao delituoso poderiam ser o suplício (atuação sobre o corpo), mais tarde passou a combinar com execração pública, e por fim, no século XVIII, a prisão. A pena para o mesmo delito sofre mudança na forma de julgamento e de punição ao longo do tempo. A prisão finalmente passa a ser a forma mais usual, econômica e possibilitaria o controle do espírito e do corpo do delituoso. "Existia um lugar físico, uma organização dos espaços chamado prisão. [...] E a prisão, como se verá, surge somente com 0 sistema capitalista de produção" (PAVARINI, 2002, p. 19). A prisão passa a ser o laboratório de saber sobre o crime. "A ciência criminológica nasce com o aparecimento do sistema capitalista e acompanha as vicissitudes da sociedade burguesa" (PAVARINI, 2002, p. 22).

Da Idade Média, em que o controle das pulsões era bastante reduzido, até os nossos dias, as classes dirigentes foram lentamente modelando a vida social e a espontaneidade deu lugar à regra e à repressão na vida privada. Passa este comportamento refinado a circular também para as classes subalternas. O sociólogo Norbert Elias, num estudo chamado $\mathrm{O}$ processo civilizador, em que integra a história, a teoria social e a psicanálise, aponta para um processo evolutivo da coerção sutil sobre os costumes, mudando a constituição psíquica das pessoas, mudando regras sociais, a percepção do indivíduo sobre elas, modificando comportamentos e sentimentos.

A pressão para transformar essas inclinações, exercida sobre o indivíduo pela sociedade, porém, é mínima em comparação com a de hoje. Os sentimentos de repugnância, desagrado ou nojo despertados por tal comportamento são, nos termos do antigo padrão, incomparavelmente mais fracos que os nossos (ELIAS, 1994, p. 146).

Revista de Filosofia, Curitiba, v. 18 n. 21, p. 27-44, jul./ dez. 2005. 
Estas sutis coerções geram, lentamente, com estímulos negativos ou positivos, nova formatação comportamental, não planejada ou racionalizada, mas sentida, conformando ao longo do tempo um refinamento chamado civilização. Norbert Elias usa a técnica de análise dos discursos sobre comportamento à mesa, sobre o uso do garfo ou lenço, sobre as recomendações dos manuais de civilização.

A sociedade construiu um padrão comportamental - civilizou-se - observando e controlando atitudes de relacionamento e convivência, com tecnologia de admoestação, constrangimento ou repressão. Estas são tecnologias de ante-sala do judiciário e da prisão. A polícia, por exemplo, surge em Londres por necessidade dos grandes comerciantes controlar as docas e armazéns para não ser pilhados pela população nos motins. A polícia é criada por necessidade privada daqueles que comandavam o poder político, passa a fazer parte do estado e atualmente faz parte da sociedade panóptica, que vigia, controla e corrige.

Foucault estuda o controle e as práticas sociais mediante uma análise histórica, pois na medida em que se alteram a estrutura social e 0 ambiente político, mudam-se as formas de coerção e controle social.

Têm-se assim esses projetos, esses textos e até esses decretos adotados pelas Assembléias. Mas, se observarmos o que realmente se passou, como funcionou a penalidade algum tempo depois, por volta de 1820, no momento da Restauração na França e da Santa Aliança na Europa, percebemos que o sistema de penalidades adotado pelas sociedades industriais em vias de formação, em vias de desenvolvimento, foi inteiramente diferente do que tinha sido projetado alguns anos antes. Não que a prática tenha desmentido a teoria, porém ela se desviou rapidamente dos princípios teóricos que encontramos em Beccaria e Bentham (FOUCAULT, 2001, p. 83).

A análise feita por Michel Foucault desnuda o encarceramento, suas mudanças e conceitos ao longo do tempo. É preciso livrar-se da ilusão de que tais idéias e práticas têm origem meramente nos fundamentos da racionalidade, pois as práticas sociais fazem aparecer novos conceitos que geram novas práticas e novos domínios do saber.

A afetividade do comportamento e experiência humanos, o controle de emoções por limitação externa e interna, promove transformações gerais na sociedade ao longo do tempo. "Pessoas isoladas no passado não planejaram essa mudança, essa civilização, pretendendo efetivá-

Revista de Filosofia, Curitiba, v. 18 n. 21, p. 27-44, jul./dez. 2005. 
la gradualmente através de medidas conscientes, racionais, deliberadas. Claro que não é [...] o resultado de um planejamento calculado em longo prazo" (ELIAS, 1993, p.193). Tanto para Elias como para Foucault, o desenvolvimento da coerção não é baseado apenas em fundamentos da racionalidade.

Elias usa como método a análise da linguagem inscrita nos manuais de orientação comportamental e de etiqueta, dizendo que os fenômenos humanos "nada mais são que concretização de relações e comportamento, materialização da vida social e mental. Isto se aplica à fala, que nada mais é que relações humanas transformadas em som" (ELAS, 1994, p. 125). Estendo este raciocínio ao conceito linguagem que engloba escrita, fala e outros signos, por conseguinte materializadores da cultura.

Foucault aborda os mecanismos de coerção mais contundentes e diz que há uma formatação comportamental pela via da disciplinarização - o foco está no corpo.

Elias aborda o tema analisando os mecanismos mais sutis e diz que há formatação comportamental pela via do condicionamento - 0 foco está na psique.

Ambos apontam para a evolução dos mecanismos de coerção, sendo inerentes à configuração do poder estatal. A configuração do estado parte da apropriação das sanções sociais sutis e dos mecanismos de atuação sobre o corpo transformada em poder político e princípios de direito. Parte da linguagem cotidiana oral ou escrita, da ação privada, para a formalização escrita da norma, sendo possível, portanto, perceber a atuação do poder coercitivo cotidiano pela análise da linguagem, sendo a oficial apenas uma parte dela. Vasculhando como arqueólogo, a forma da linguagem usual para a coerção, perceberemos o verdadeiro poder e sua origem.

O mecanismo da detenção (prisão, internamento) seria ao mesmo tempo um castigo exemplar, a eliminação da convivência social, bem como uma oportunidade de correção, segundo a 'verdade' predominante no meio social e protagonizada pelas estruturas e agentes do governo. "[...] as condições políticas, econômicas de existência não são um véu ou um obstáculo para os sujeitos de conhecimento, mas aquilo através do que se formam os sujeitos de conhecimento e, por conseguinte, as relações de verdade" (FOUCAULT, 2001, p.27). A prisão, tendo a função de apartar a pessoa para que não continue cometendo

Revista de Filosofia, Curitiba, v. 18 n. 21, p. 27-44, jul./ dez. 2005. 
mal à sociedade, tendo a função de punir para que os demais da sociedade tenham temor a ela e tendo a função de corrigir o desvio para poder devolver a pessoa ao convívio regular, acaba sendo um mecanismo que produz saberes disciplinantes ou coercitivos.

As Ciências Humanas orientarão na elaboração dos conceitos por meio de um saber clínico que, por sua vez, implicarão no surgimento de normas e regras do cotidiano (não jurídicas) e Leis. O exame cria saberes para a criminologia, psiquiatria, pedagogia e medicina, ele identifica naquele que cometeu um delito o grau de anormalidade ou periculosidade e lhe dá uma classificação, determinando o tipo de procedimento de controle e recuperação, que resulta num controle políticocientífico do meio (FOUCAULT, 2000, p. 93). O inquérito e o exame, a par do subpoder, são formas de saber-poder ao nível da produção e da constituição, geradores de uma linguagem própria reflexo de um conceito sobre o sujeito. A Medicina, por exemplo, como afirma Michel Foucault $(2000,97)^{2}$, pode exercer um controle médico e autoritário sobre a população, uma assistência-controle.

O saber ou o conhecimento, tomado pelo exame e o inquérito, junto ao sujeito, gera um conceito, uma 'verdade', que é transformada em regras e Leis pelo poder. Essas 'verdades', esses conceitos, também penetram em todos os poros sociais, criando a sociedade disciplinar. Para punir, deter e controlar, não se inventa nada de novo, e sim, adaptam-se mecanismos de coerção que vão desde a prisão até a humilhação pública, passando pelo controle do tempo e do espaço. Existe, "[...] de um lado, um sistema de direito, sábio e explícito - o da soberania - e de outro, as disciplinas obscuras e silenciosas trabalhando em profundidade, constituindo o subsolo da grande mecânica do poder" (FOUCAULT, 2000, p. 189).

\section{As especialidades da coerção denotada pela linguagem}

Vasculhando os registros da Escola para Menores Queiroz Filho, no Paraná, retiramos algumas frases sobre os adolescentes infrato-

2 “[...] uma Medicina que é essencialmente um controle da saúde e do corpo das classes mais pobres para torná-las mais aptas ao trabalho e menos perigosas às classes mais ricas".

Revista de Filosofia, Curitiba, v. 18 n. 21, p. 27-44, jul./dez. 2005. 
res, entre 1958 e 1992, que denotam a atuação do poder dos agentes do estado sobre os internos:

- Conduta que diverge dos valores morais

- Personalidade para fins delituosos

- Possui potencial produtivo

- Tem boa aparência

- Obediência aos superiores

- Atitude típica de pessoa primitiva

Essas frases avaliam o infrator em relação a um comportamento esperado. Comportamento desejado pela norma legal ou pelos agentes da instituição, segundo seus padrões culturais. Pela linguagem, é possível descortinar e perceber a atuação do poder do estado e o poder não estatal, que o próprio estado desconhece. O poder que opera de forma sutil ou contundente, por todos os poros da sociedade e os mecanismos coercitivos que usa para conformar o corpo ou o comportamento: aparência, produtividade, valores morais, etc.

Tanto na escola como na prisão ou no hospital, o controle pressupõe controle do tempo, do espaço (arquitetura) e do corpo e exige o exame para o enquadramento de cada um, para a criação de um saber clínico sobre ele. São instrumentos reais de formação e de acumulação do saber: métodos de observação, técnica de registro, procedimento de inquérito e de pesquisa, que são aparelhos de verificação.

Contra o crime, no nosso caso a infração, o saber/poder vai atuar com os mecanismos desenvolvidos ao longo do tempo e apropriado pelo estado numa dupla função: na punição do delito e no controle da criminalidade. A punição já pode ser considerada uma forma de interferir ou desestimular o fenômeno social da criminalidade. A correção, a educação e a integração social são as palavras que compõem a linguagem dos que usam a prisão para disciplinar o corpo e a mente do interno para devolvê-lo 'curado' para a sociedade.

Em nosso caso, a coerção atua em favor da sociedade disciplinar tolhendo a liberdade humana natural, pois, "por termos nascidos livres e indeterminados, conquistamos o amargo privilégio da errância, do erro, e de sua crispação exacerbada e desesperada: o crime" (PELLEGRINO, 1992, p. 102). O tolhimento da liberdade natural mais usado é a prisão, na medida em que é amplamente aceita, tem rituais inscritos na lei e conduzido pelo judiciário, com o objetivo maior de controle social.

Revista de Filosofia, Curitiba, v. 18 n. 21, p. 27-44, jul./ dez. 2005. 
Na medida em que se pune o crime, impõe temor à criminalidade. Na medida em que recompensa, corrige e atua sobre o corpo para atingir a alma do criminoso, alimenta a tese de que devolverá à sociedade um indivíduo que sabe controlar a sua liberdade natural. A coerção é um fenômeno histórico e social, atua contra o crime não só para vingar ou punir (como em épocas passadas), mas ao tempo em que processa a punição e a vingança social, atua como mecanismo de controle da criminalidade. $\mathrm{O}$ encarceramento ou prisão é o mecanismo de coerção em que percebemos o uso intensivo de inúmeras e desenvolvidas tecnologias de disciplinamento social.

A justiça norteia-se pela definição do que pode ou não pode se fazer na sociedade (a lei), tendo atuação efetiva depois do delito ocorrido. Antes do evento criminoso, temos o controle e a vigilância, sendo a polícia o mecanismo mais usual.

A criminalidade, embora corretamente avaliada como sintoma, nem por isto pode dispensar o tratamento policial conveniente. Há que reprimir, com severidade, os atos anti-sociais de delinqüência, de pobres e ricos. Há que aumentar a eficiência material e moral do aparelho de polícia (PELLEGRINO, 1984).

Depois da polícia e da justiça, a infração é punida e a criminalidade é controlada, pelo mecanismo histórico chamado prisão. Este mecanismo é mais eficiente e econômico que o controle binário germânico, que a deportação, que o trabalho forçado, que a reparação, que os mecanismos de escândalos, que a pena de talião, que o suplício medieval. "Esses projetos bem precisos de penalidades foram substituídos por uma pena bem curiosa [...]: trata-se do aprisionamento, da prisão. [...] Surge no início do século XIX como uma instituição de fato, quase sem justificação teórica" (FOUCAULT, 2001, p. 84).

Sob o ponto de vista de uma instituição que encarcera para atender as funções de controle (punição e correção) é que analisamos a Escola Queiroz Filho. Ao fenômeno social da infração, o mecanismo de coerção usado é o da detenção em um "local de residência e trabalho onde um grande número de indivíduos com situação semelhante, separados da sociedade ampla por considerável período de tempo, levam uma vida fechada e formalmente administrada", ou seja, o infrator é internado numa instituição total (GOFFMAN, 2003, p. 11).

Revista de Filosofia, Curitiba, v. 18 n. 21, p. 27-44, jul./dez. 2005. 
As instituições totais podem ser de vários tipos, desde manicômios, conventos, quartéis e prisões. Elas rompem com a possibilidade da pessoa brincar, trabalhar e dormir em diferentes locais, sob diferentes autoridades e sem a observância permanente de um plano racional de regras. Numa instituição total, estas atividades são realizadas no mesmo local e sob uma única autoridade, observando que os internos deverão fazer as mesmas coisas em conjunto, com atividades diárias com rigor de horário. Erving Goffman (2003) afirma que cadeias, penitenciárias, campos de prisioneiros de guerra, campos de concentração são exemplos de um tipo de instituição total "organizado para proteger a comunidade contra perigos intencionais, e o bem-estar das pessoas assim isoladas não constitui o problema imediato" (GOFFMAN, 2003). Não constitui problema nem para si, pois tem as necessidades básicas atendidas, e nem para sociedade, pois estão apartadas. A exceção deste "bem-estar" está em relação ao tolhimento da liberdade.

No século XIX, a detenção penal toma o lugar dos suplícios e das teorias reformadoras. Com a estatização da polícia e da justiça, passamos a ter uma sociedade controlada, disciplinada pelas prisões. A prisão perfeita seria o panóptico concebido pela arquitetura para que 0 preso, de uma torre central, seja permanentemente visto, vigiado e submetido a uma análise de comportamento, com economia de recursos. Este saber disciplinar é transformado em poder que atua sobre outras instituições; "a fábrica, a escola, a prisão ou os hospitais têm por objetivo ligar o indivíduo a um processo de produção, de formação ou de correção dos produtores" (FOUCALT, 2001, p.114). A função destas instituições não é mais a de controlar o tempo dos indivíduos, mas a de controlar seus corpos. Nem tanto para a correção, mas para a produção.

O contexto capitalista cria um conjunto de técnicas que transforma o corpo e o tempo dos homens em tempo e força de trabalho, não forçado por um poder hegemônico, identificado numa classe ou num fenômeno maciço engendrador, mas numa trama capilar de poder, que cria o disciplinado, que também disciplina, fazendo de todos agentes de produção. O estado capitalista adotou e adaptou os mecanismos coercitivos criados historicamente. As instituições disciplinadoras não foram criadas pelos capitalistas, porém geraram saberes que foram potencializados por eles para criar uma sociedade disciplinar. Nesse caso, o indivíduo é efeito do poder e também centro de transmissão, por meio da família, vizinhança, escola, médicos, professores e outros agentes reais

Revista de Filosofia, Curitiba, v. 18 n. 21, p. 27-44, jul./ dez. 2005. 
do cotidiano, não articulados pela burguesia, mas que são mecanismos de poder que começaram a se tornar econômica e politicamente úteis, absorvidos, então, pelo capitalismo.

[...] não foi a burguesia que achou que a loucura devia ser excluída ou a sexualidade infantil reprimida. Ocorreu que os mecanismos da exclusão da loucura e de vigilância da sexualidade infantil evidenciaram, a partir de determinado momento e por motivos que é preciso estudar um lucro econômico e uma utilidade política, tomando-se, de repente, naturalmente colonizados e sustentados por mecanismos globais do sistema do Estado (FOUCAULT, 2000, p. 185).

A prisão é a institucionalização do poder de punir, atuando sobre o indivíduo, tornando-o obediente, sujeito a hábitos, regras e ordens. O corpo é treinado, corrigido por um sistema de autoridade, por uma 'ortopedia', que o corrige individualmente. Ao final do século XVIII, temos três dispositivos das tecnologias de poder: o suplício, a representação e a reeducação. É o surgimento da disciplina, tornando os corpos dóceis, na prisão, no quartel ou na escola; controlando o tempo por meio de horários para as atividades e o descanso, controlando os espaços com uma arquitetura específica, dispondo o poder com uma hierarquia vigilante. Surge também o exame, que permite qualificar, classificar e punir, que é um investimento político no campo do saber para que 0 indivíduo passe a ser objeto de poder. $\mathrm{O}$ mundo prisional tem mecanismos singulares de controle da pessoa e garantidor do convívio, que vão desde o espaçamento físico, passando pela postura corporal até a linguagem. Existe uma ética própria entre os internados, entre os dirigentes e entre estes dois grupos.

Numa prisão (instituição total) existem dois grupos sociais bem distanciados que são obrigados à convivência mútua: um grande grupo de internados e uma pequena equipe de supervisão. Esta tem interação com o mundo exterior, sentem-se superiores e corretos e vêem os internados como amargos e não merecedores de confiança. Enquanto o grupo maior tende a perceber os dirigentes como mesquinhos e arbitrários, sentindo-se inferiores, censuráveis e fracos. "Cada agrupamento tende a conceber o outro através de estereótipos limitados e hostis" (GOFFMAN, 2003, p. 19). A distância social é freqüentemente prescrita, na conversa, nos planos da instituição, no trabalho e outras atividades. "Desenvolvese dois mundos sociais e culturais diferentes, que caminham juntos com

Revista de Filosofia, Curitiba, v. 18 n. 21, p. 27-44, jul./dez. 2005. 
pontos de contato oficial, mas com pouca interpenetração" (GOFFMAN, 2003, p. 20). A utilidade deste procedimento está na condição de controle de um grande grupo por parte dos supervisores. As regras, o horário, a linguagem, a divisão e a ocupação do espaço e a burocracia possibilita a distância e o controle com relação ao grande grupo de internados.

O juízo de apreciação ante a conduta humana, que é suscetível de qualificações do ponto de vista do bem e do mal, ou entre o certo e o errado, é chamado de ética. O mundo prisional cria regras de comportamento por um ajustamento social e psicológico, que são avaliados, punidos ou reforçados, perante esta nova sociedade. Esta nova sociedade carcerária está encerrada num espaço que força a convivência, tendo basicamente de um lado os internos e de outros os dirigentes. Esta ética prisional gera mecanismos de coerção processando a adaptação a esta nova situação. Uma atitude que no mundo externo é aceita com naturalidade pode não ser aceita internamente, tanto pelos dirigentes, quanto pelos internos. A ética prisional é um ajuizamento de valores perante esta sociedade interna e tem regras a cumprir e padrões não formais de tolerância e convivência mútuas.

Aqueles que estão chegando à prisão pela primeira vez, certos de que vão encontrar elementos hostis, procuram demonstrar aos outros que são bandidos perigosos, dignos de todo respeito e consideração. Essa falsa aparência pode resultar em mortes e agressões. Porque, segundo os complicados conceitos éticos próprios de cidade-presídio, aqui dentro só pode haver um valente por setor - jamais dois (SOUZA, 1976, p. 16).

É construído novo padrão de comportamentos, coerções motivadas por esta ética prisional, pois são relações sociais impostas, grupos etários e étnicos distintos, forçados a dormir no mesmo quarto, comer da mesma comida, obrigados a medicar-se, não importunar o sono da maioria, cuidar da higiene e das palavras proferidas, etc. "O internato não pode fugir facilmente da pressão de julgamentos oficiais e da rede envolvente de coerção" (GOFFMAN, 2003, p. 44). É um "mundo fora do mundo" (SOUZA, 1976, p. 66).

Erving Goffman (2003) aponta alguns processos característicos desenvolvidos dentro das instituições: a perda da competência adulta, em que a autonomia da pessoa é diminuída; passa a ter comportamentos escolhidos ou pelo dirigente ou por seus colegas; há perda das comodi-

Revista de Filosofia, Curitiba, v. 18 n. 21, p. 27-44, jul./dez. 2005. 
dades materiais; renúncia de sua vontade e controle da linguagem e compreensões de novas expressões. "O internado pode também descobrir o emprego de um tipo retórico de linguagem. Algumas perguntas por exemplo, Você já tomou banho? ou Você colocou as duas meias? podem ser acompanhadas pelo exame simultâneo que fisicamente revela os fatos, o que torna supérfluas as perguntas"(GOFFMAN, 2003, p. 47).

Uma ilustração semelhante nos traz o jornalista Percival de Souza quando conviveu com os presos do Carandiru em São Paulo:

Certa vez, um juiz criminal cometeu um lamentável equívoco. Ele fez questão de vir comunicar a transferência pessoalmente. Chamou um dos presos, e o cumprimentou: Parabéns, meu filho, você foi premiado. O preso recuou, espantado: Pelo amor de Deus, doutor. O juiz não entendeu a reação. Um funcionário sorrindo, explicou ao juiz que premiado, na linguagem da cidade-presídio, tem outro significado: quer dizer que o detento recebeu uma nova condenação (SOUZA, 1976, p. 90).

Sobre a imposição de comportamento, apresentamos estes exemplos: "Entendi por que os suicídios acontecem de manhã, depois de noites de depressão ou pânico claustrofóbico, espremidos entre os outros, sem poder chorar: - Homem que chora na cadeia não merece respeito" (VARELLA, 1999, p. 49). "Aprende-se a chorar em silêncio. Ninguém quer ser surpreendido chorando - e, pela lei do cão, todo aquele que chora é medíocre e covarde. Afinal, - Cadeia foi feita pra homem" (SOUZA, 1976, p. 19). A expressão 'lei do cão' é uma das denominações que recebe esta ética prisional.

A perda da autonomia, assumindo um comportamento diferenciado, observamos neste detalhe apresentado pelo médico Dráuzio Varella, enquanto convivia com os presidiánios do Carandiru: "Durante 0 banho, observei que eles entravam embaixo do cano com as costas quase encostadas na parede. Comentei o fato com seu Manoel, que explicou: - Ladrão nunca fica de bunda para os outros, doutor!" (VARELA, 1999, p. 127). Esta postura está diretamente ligada ao fato da convivência coletiva forçada, associada à abstinência sexual.

Erving Goffman (2003) descreve que entre os fatos que impõem novas atitudes está a mortificação do eu produzidos pelos mecanismos de coerção "para controlar a vida diánia de grande número de pessoas em espaço restrito e com pouco gastos de recursos" por parte do sistema,

Revista de Filosofia, Curitiba, v. 18 n. 21, p. 27-44, jul./dez. 2005. 
produzindo aguda tensão psicológica no indivíduo (GOFFMAN, 2003, p. 48). Passa então por um processo de reorganização interna com a observação das "regras da casa", apresenta um pequeno número de prêmios ou privilégios - que contrasta com o ambiente rígido - e há os castigos com conseqüência de desobediência às regras. Convém relembrar aqui que já apontamos que a coerção age com estímulos negativos ou positivos, encorajando ou reprovando aspectos comportamentais.

Para enfrentar um prejuízo à mortificação, as pessoas passam para um ajustamento, "desenvolvem apoio mútuo e resistência a um sistema que as forçou à intimidade numa única comunidade igualitária de destino" (GOFFMAN, 2003, p. 55). Também desenvolvem um movimento moral num sentido de injustiça comum e de amargura ao mundo externo, passam a uma solidariedade por congregação numa região fisicamente próxima, constroem panelinhas ou pares em que dois internos ficam mutuamente dependentes na assistência e apoio emocional (GOFFMAN, 2003, p. 58).

Estas e outras ações constituem condições para diferentes táticas de adequação ao mundo carcerário. "Tais condições permitem diferentes maneiras individuais de adaptação, além de qualquer esforço de ação subversiva coletiva" (GOFFMAN, 2003, p. 59, grifo nosso). Existe a tática do afastamento da situação, em que o interno deixa de dar atenção a tudo e se ocupa dos acontecimentos que o cerca; existe a tática de rejeição constante da instituição, onde deixam de cooperar; outra tática é a de aceitar o pouco do mundo externo oferecido como o suficiente e gerador de satisfação, e por fim, a tática da conversão ao modelo e de concordância com tudo da instituição. Esta última tática cria o famoso dedo-duro, útil aos dirigentes para ter informações de controle sobre a massa (GOFFMAN, 2003, p. 61). Estas táticas são de duração limitada, sobretudo se afrontarem demais as exigências comportamentais exigida pela maioria.

A realidade material da prisão mais os processos psicossociais (mortificação, adaptação e ajustamento) criam um caldo indutor a novas atitudes perante o grupo. Surge uma ética prisional, com regras de uso interno singular, baseado nas exigências de controle das emoções, das pulsões sexuais, do barulho, do odor, para dividir os espaços (cama, cela, cadeira, pavilhão, etc.), retribuir ou pagar por benefícios recebidos e da observância das regras para receber visitas ou tomar sol.

Revista de Filosofia, Curitiba, v. 18 n. 21, p. 27-44, jul./ dez. 2005. 
Em cativeiro, os homens, como os demais grandes primatas [...] criam novas regras de comportamento com o objetivo de preservar a integridade do grupo. Esse processo adaptativo é regido por um código penal não escrito, como na tradição anglo-saxônica, cujas leis são aplicadas com extremo rigor: - Entre nós, um crime jamais prescreve, doutor. Pagar a dívida assumida, nunca delatar o companheiro, respeitar a visita alheia, não cobiçar a mulher do próximo, exercer a solidariedade e o altruísmo recíproco, conferem dignidade ao homem preso. O desrespeito é punido com desprezo social, castigo físico ou pena de morte: - No mundo do crime, a palavra empenhada tem mais força do que um exército (VARELLA, 1999, p. 10).

\section{Segundo Michel Foucault:}

Se o princípio da pena é sem dúvida uma decisão de justiça, sua gestão, sua qualidade e seus rigores devem pertencer a um mecanismo autônomo que controla os efeitos da punição no próprio interior do aparelho que os produz. Todo um regime de punições e de recompensas que não é simplesmente uma maneira de fazer respeitar o regulamento da prisão, mas de tornar efetiva a ação da prisão sobre os detentos (FOUCAULT, 1999, p. 206).

A prisão, com as regras rígidas impostas pelo dirigente e com as sutis ou contundentes coerções internas geradoras de uma ética prisional, passa historicamente a ser peça do conjunto de punições ao crime e mecanismo auxiliar no controle da criminalidade.

Rudá de Andrade, cineasta, filho de Oswald de Andrade, foi confundido como traficante e fica preso na França por dez meses. Ele dá a dimensão do poder coercitivo envolto na prisão, pois chama este período de "estágio cultural" e escreve uma poesia concretista chamada Panfleto do Prisioneiro: “A grade agride, agrade" (ANDRADE, 1983, p. 110).

Há um outro mundo sociocultural configurado pela imponência da grade descortinado pela análise da linguagem.

\section{Referências}

ANDRADE, Rudá de. Cela 3. São Paulo, SP: Brasiliense, 1983.

ARRUDA, Geraldo Amaral. A linguagem do juiz. São Paulo, SP: Saraiva, 1997. 
CO LO MBO, Irineu M. O adolescente infrator e o sistema de ensino paranaense: a trajetória da Escola para Menores Professor Queiroz Filho (1965-1992). Curitiba, 2002. Dissertação (Mestrado em Educação) - Departamento de Educação, Universidade Federal do Paraná.

CUNHA, Maria Clementina Pereira. 0 espelho do mundo: Juquery, a história de um asilo. Rio de Janeiro, RJ: Paz e Terra, 1986.

FAUSTO, Boris. Crime e cotidiano. 2. ed. São Paulo: Editora da Universidade de São Paulo, 2001.

ELIAS, Norbert. 0 processo civilizador: uma história dos costumes. Rio de Janeiro, RJ: Jorge Zahar, 1994. v. 1.

. O processo civilizador: formação do Estado e civilização. Rio de Janeiro, RJ: Jorge Zahar, 1993. v. 2.

EWALD, François. Foucault: a norma e o direito. Lisboa: Vega, 2000. FOUCAULT, Michel. A verdade e as formas jurídicas. Rio de Janeiro, RJ: Nau, 2001.

. Microfísica do poder. 15. ed. Rio de Janeiro,RJ: Graal, 2000 .

. The birth of the clinic: an archaeology of medical perception. New York: Vintage Books, 1994.

. Vigiar e punir: nascimento da prisão. 20. ed. Petrópolis: Vozes, 1999.

GAGNEBIN, Jeanne Marie. Sete aulas sobre linguagem, memória e história. São Paulo, SP: Imago, 2000.

GOFFMAN, Erving. Manicômios, prisões e conventos. São Paulo, SP: Perspectiva, 2003.

MELOSSI, Dario. El estado del control social. Madrid: Siglo XXI de España Editores, 1992.

O'BRIEN, Patricia. A história da cultura de Michel Foucault. In : HUNT, Lynn. A nova história cultural. São Paulo, SP: Martins Fontes, 2001.

Revista de Filosofia, Curitiba, v. 18 n. 21, p. 27-44, jul./dez. 2005. 
PAVARINI, Massimo. Control y dominación: teoria criminológicas burguesas y proyecto hegemônico. Buenos Aires: Siglo XXI Editores Argentina, 2002.

PELIEGRINO, Hélio. A burrice do demônio. Rio de Janeiro, RJ: Rocco, 1992.

. Psicanálise da criminalidade brasileira: ricos e pobres. Jornal Folha de São Paulo, Folhetim, 07 de outubro de 1984.

SOUZA, Percival de. A prisão: história dos homens que vivem no maior presídio do mundo. São Paulo, SP: Alfa-ômega, 1976.

THOMPSON, E. P. Costumes em comum: estudos sobre a cultura popular tradicional. São Paulo, SP: Companhia das letras, 1998.

VARELLA, Dráuzio. Estação Carandiru. São Paulo, SP: Companhia das Letras, 1999.

Recebido em/ Received in: 14/02/2005 Aprovado em/ Approved in: 05/04/2005 